\title{
The Metaphysics and Epistemology of Settling: Some Anscombean Reservations
}

\author{
ALEC HINSHELWOOD \\ University College London, UK
}

(Received 5 June 2013)

\begin{abstract}
Helen Steward accepts what I call the Separation Thesis, the main tenet of which is that the movements one's body makes when one acts are the causal results of one's actions. I claim that this threatens to generate a pair of epistemic shortfalls: first, our perception of others' bodily movements may not reach to their actions themselves; and, second, our own 'knowledge in intention' may not reach to the actual bodily movements in which the efficacy of our actions consists. I suggest we should adopt a slogan that Anscombe considered, and say 'I do what happens' when I am acting. Then the movements one's body makes when one acts are seen simply to be one's actions.
\end{abstract}

I.

In the context of discussing the control that agents exercise over their bodies, Helen Steward offers the following metaphor:

I am in charge in the way that a government minister is in charge of a department. No minister directly controls all the work of a particular department or knows all the details of what is going on within it: tasks are delegated to more junior officials, and so on. But if it becomes important, a minister can step in to take a more direct interest in a particular matter. She can more closely monitor the work of the civil

Correspondence Address: Alec Hinshelwood, 5 Deane Gate Drive, Houghton-on-the-Hill, Leicestershire, LE7 9HA, UK. Email: a.j.hinshelwood@gmail.com

(C) 2013 The Author(s). Published by Taylor \& Francis.

This is an Open Access article distributed under the terms of the Creative Commons Attribution License http://creativecommons.org/licenses/by/3.0/, which permits unrestricted use, distribution, and reproduction in any medium, provided the original work is properly cited. The moral rights of the named author(s) have been asserted. 
servants beneath her, issue directives, insist on changes in working practice, or even, in extremis, take on the necessary work herself. ${ }^{1}$

The image is a striking one, and the language of supervision recurs throughout A Metaphysics for Freedom. ${ }^{2}$ However, I do not think it well captures our sense of ourselves as embodied agents: the image is one in which the agent is at some distance from her actions and what she effects by them.

It is at least partly because of Steward's acceptance of what I call the Separation Thesis that this image of ministerial supervision seems apt. She claims that we should draw a metaphysical distinction between the movements one's body makes when one acts, and one's actions themselves. This flows from her claim that actions are causings by agents of the movements of their bodies, whilst the movements that the body makes in acting are occurrences that are brought about and sustained by means of actions. So Rachael's raising her arm, for example, is to be identified with her causing of its rising, with the occurrence of the rising itself being the distinct result of her raising it. I formulate the two clauses of the Separation Thesis as follows:

- (Non-Identity Clause) Actions and the movements the body makes in acting are not identical.

- (Causal Clause) Actions are the causings of bodily movements by agents; bodily movements are the causal results of causings.

Here one's actions are the means by which one initiates, directs and supervises the movements of one's body.

In this paper I seek to show that the Separation Thesis is in tension with the following two epistemic data. First, if someone is doing something intentionally, then in many cases one can perceive her doing it, given suitable conditions. Second, that if someone is intentionally doing something, then ordinarily she herself knows what she is bringing about in acting, where what she is bringing about is being brought about intentionally; and this 'knowledge in intention' is not grounded in observation or inference.

I suggest that these data should lead us to reject both clauses of the Separation Thesis, and allow that my raising my arm and its rising are two sides of the same coin - a single occurrence wherein I causally affect my arm. Were we to baptise the merely resultant bodily movements, as Steward's account has them, as 'what happens', then on this view we should accept — on the contrary - the slogan that Elizabeth Anscombe considered: when I am acting 'I do what happens'. ${ }^{3}$

In Section II, I consider an argument in favour of the Separation Thesis which Steward might wish to endorse. In Section III, I argue that the Thesis is in tension with the first epistemic datum. In Section IV, I consider an objection to the

\footnotetext{
${ }^{1}$ Steward, A Metaphysics for Freedom, 51.

${ }^{2}$ Ibid., 52, 68, 162, 165.

${ }^{3}$ Anscombe, Intention, Section 29.
} 
argument in Section III and introduce two ways of thinking about bodily movements. In Sections V-VI, I press that the Separation Thesis is in tension with the second epistemic datum. I close in Section VII by reconsidering the argument that might be supposed to support the Separation Thesis.

\section{II.}

It is helpful to begin with a class of verbs we employ when speaking of actions. ${ }^{4}$ Take 'move'; this verb can appear transitively or intransitively, and the two uses are systematically related. So we can say 'I move my arm' and 'my arm moves', and it seems to be true that I cause my arm to move if I move my arm. More generally, where a verb's transitive and intransitive versions are so related, we can use the subscripts ' $T$ ' and ' $\mathrm{I}$ ' to distinguish the two uses in the following schema:

(S) If $a \varphi$-S $b$, then $a$ causes $b$ to $\varphi_{\mathrm{I}}$.

At least on the face of it verbs like 'break', 'close', 'melt', 'burn' and 'raise' conform to (S), and apply univocally to both animate and inanimate agents (though of course there are plenty of other 'causal' verbs for ascribing action which do not conform).

Now take the noun-phrase 'the movement of my arm'; this might be taken to refer either to the movement $\mathrm{T}_{\mathrm{T}}$ of my arm by me - my moving it —or to the movement $t_{I}$ my arm makes - its moving. And, arguably, these cannot refer to the same thing, for if we assume that actions are causings of movements ${ }_{\mathrm{I}}$, then we cannot identify them with movements. To see this, transpose an instance of (S) into the present progressive:

(1) If I am moving my arm, then I am causing my arm to move.

Then assume the following:

(2) If I am causing my arm to move, then there is an event of my arm's moving occurring.

(3) My moving my arm is identical with the causing of an event of my arm's moving.

And then, for reductio, assume:

(4) My moving my arm is (an event which is) identical with an event of my arm's moving.

We obtain an absurd result:

(5) My moving my arm is an event which is causing itself.

${ }^{4}$ See Hornsby, Actions. 
It is natural enough, then, to suppose that we must reject (4), and, although the foregoing argument is not Steward's own, it coheres with how she sees things: ${ }^{5}$ "Actions cannot be identified with bodily movements I $_{\text {for }}$ bodily movements are not doings, they are rather the results or effects of such things. ${ }^{6}$ Or, as she later asks rhetorically, 'If Alf caused his body to move, then surely he caused an event that was a movement of his body?"

Premise (3) here amounts to the assumption of the Causal Clause of the Separation Thesis, adding only that the resultant bodily movements are events. The denial of the identity between actions and bodily movementsthe Non-Identity Clause- then follows.

Three further ideas are important for understanding Steward's view. First, Steward insists that our actions are causings of movements by us, because we need something in the progressive in order to capture the on-going role of the agent throughout the course of her activities. So she writes: '[Causings] may be thought of as taking place alongside, and at the same time as, the movements and changes that are thereby effected. ${ }^{8}$ Second, Steward says that the causings of our bodily movements by us are exercises of two-way powers. Thus Steward's agent is said neither to cause her actions nor to cause events that are actions in virtue of being so caused. Causings simply are our actions. Third, Steward claims that actions are processes, not events; I return to this in Section IV. ${ }^{9}$

\section{III.}

Anscombe makes the following report, early on in Intention:

I am sitting in a chair writing, and anyone grown to the age of reason in the same world would know this as soon as he saw me, and in general it would be his first account of what I was doing; if this were something he arrived at with difficulty, and what he knew straight off were precisely how I was affecting the acoustic properties of the room (to me a very recondite piece of information), then communication between us would be rather severely impaired. ${ }^{10}$

Whatever dialectical role these remarks play in the context of Anscombe's argument, she seems to be voicing something plainly true-namely, that we can perceive what someone is doing simply by seeing her doing it. So let me pose the question: If in acting what someone does is to cause distinct

\footnotetext{
${ }^{5}$ The argument is basically the one espoused by Alvarez and Hyman, 'Agents and Their Actions', 228-9.

${ }^{6}$ Steward, A Metaphysics for Freedom, 33.

${ }^{7}$ Ibid., 201.

${ }^{8}$ Ibid., 46.

${ }^{9}$ Ibid., 45.

${ }^{10}$ Anscombe, Intention, 8 .
} 
occurrences whose completion her action requires, can one perceive another person's acting? I suggest that one cannot.

Now, neither Steward nor I harbour doubts about the perceptibility of occurrences; nor do we wish to endorse scepticism of a Humean sort about the perceptibility of one thing's causing another. ${ }^{11}$ In fact, Steward herself initially introduced the notion of a causing as distinct from that of a cause precisely to allay worries about the invisibility of action. ${ }^{12}$ For, if one thinks of an agent's action as an event that causes and so precedes a bodily movement, then it seems as if the only place to find it is inside the agent's body, perhaps in her brain. But if that is so, then it looks as if, strictly speaking, actions are unavailable to the naked eye. Causings, however, are exercises of powers attributable to whole agents rather than their parts - internal or otherwise. So, given that we should say both that we can see Rachael and her arm's rising, what could prevent us from saying we see Rachael's raising her arm when she is raising it? No doubt that is what we would be inclined to say on entering a room and witnessing Rachael raising her arm. After all, causings are continuous with their resultant events and so forestall any worries about the action's being over by the time we witness the observable events.

It bears emphasizing that the epistemological desideratum here is the possibility of actions themselves figuring as direct objects of perception. ${ }^{13}$ My concern, however, is as follows. Imagine entering the room and seeing Rachael, who is successfully raising her arm. As noted we would no doubt say that we could see Rachael raising her arm, but as Hornsby says

It is very natural to identify someone's raising her arm with her arm's going up. When one sees what goes on when someone raises her arm, one cannot perceptually discriminate between her changing the position of her arm and the position of her arm's changing. ${ }^{14}$

Perhaps an implicit denial of the Separation Thesis lies behind our saying we can see the action itself, that is, Rachael's raising of her arm. For, if we were told that the obviously visible occurrence of her arm's going up is not her action but something distinct in which her action results, then we might be unsure whether we really can literally see the action itself. It would not obviously help here to be told that, nevertheless, the action was occurring whilst the arm was rising; I think one would be unsure where else to look to see it. What else could one see, the seeing of which would count as one's

\footnotetext{
${ }^{11}$ On this, see Anscombe, Collected Philosophical Papers, Ch. 13.

${ }^{12}$ Steward, 'Do Actions Occur'.

${ }^{13}$ To that extent I ignore possible epistemological responses to the problem which would secure our seeing actions (or perhaps that someone is acting) indirectly, on account of our seeing the resultant occurrences. For discussion of one such strategy with respect to scepticism about other minds, see Dretske, 'Perception and Other Minds'.

${ }^{14}$ Hornsby, 'Actions and Activity', 234.
} 
having seen the action? It seems that there is nothing else available for one to perceive - not even if one were armed with a microscope or an fMRI scanner -which could bring one closer to seeing the action itself.

It seems that we should make the identification that Hornsby suggests is natural: Rachael's raising her arm is identical with its rising. If that is right, then there is no problem about our seeing actions.

\section{IV.}

The identification may be natural but that hardly makes it mandatory, let alone correct. Perhaps perceptually indistinguishable things may be distinct. A bronze statue and the lump of bronze out of which it is formed are perceptually indistinguishable but (arguably) distinct nonetheless. They differ in their modal properties: the lump could persist through its being melted down whereas the statue could not. ${ }^{13}$

With this I do not wish to quarrel. But notice that the fact that the lump and the statue are perceptually indistinguishable, despite being distinct, surely stems from the intimate relation in which the lump stands to the statue: the relation of constitution, perhaps, or so I shall assume. So, if the action case is held to be analogous, the action and the resultant movement will also need to be intimately related in some way that again permits non-identity.

It is of importance, then, to consider a way of thinking about how temporal matter might stand to an action which Steward has recently developed. ${ }^{16} \mathrm{Her}$ thought is that we might helpfully think of actions analogously to substances, which persist through changes. So the self-same arm raising could begin slowly and finish quickly, as a substance may change its size over time. Moreover, actions are modally robust: the same action could have taken longer or been completed more quickly, just as one and the same substance might have had some different parts. Coincident with each action, however, will be some portion of temporal stuff: raising or running, say, a given duration of which will make up the particular action. This is comparable to spatial stuff, as some kind of matter will make up a material substance. Steward identifies portions of temporal stuff with events and avers that they will not themselves persist through change: 'an event just consists of the temporal parts of which it consists and that variation in quality amongst those parts does not constitute a change in the event itself ${ }^{17}$ Moreover, she suggests that events have their temporal parts necessarily and so are modally fragile.

The upshot is that for any given action there will be an event, which is the coincident portion of temporal stuff. Steward calls actions processes in

\footnotetext{
${ }^{15}$ I owe this objection to Helen Steward.

${ }^{16}$ Steward, 'Actions as Processes'. Cf. Crowther, 'Matter of Events'; Hornsby, 'Actions and Activity'.

${ }^{17}$ Steward, 'Actions as Processes', 384.
} 
distinction to these coincident events and, given Leibniz's Law, a process could never be an event on Steward's view. If, in the case of Rachael's raising her arm, we took the bodily movement to be the coincident event of its rising, then we would have to grant their non-identity - despite their being perceptually indistinguishable. And notice now that we have argued for the Non-Identity Clause of the Separation Thesis without invoking the Causal Clause. But where does this leave the Causal Clause? ${ }^{18}$

It seems to me that the matter/form distinction engenders two sets of possible complications for the idea that actions are the causings of bodily movements. First, although an action and its constituent event intuitively share a temporal profile, one might think that a causing must begin, by however small a degree, at some point before the movement in which it results. But here a confusion between causings and causes must be avoided. Causes presumably do need to start before their effects. But need this be so for causings? Steward says (in a passage quoted above, Section II) that actions take place at the same time as the movements that are their effects. Even if Steward's central point there is to deny that actions have to be finished by the time their resultant events occur, it is at least open to her to spell out the notion of a causing in such a way that causings are simultaneous with their resultant, yet constituent, events. Having said that, however, if we deny that movements are the causal results of actions, there can be no difficulty in asserting the simultaneity of the two.

Second, it is plausible to think that material objects like statues asymmetrically depend, in some sense, on the matter that constitutes them. (Or at least that, in any world in which the statue exists, there will be some portion of matter on which it depends, even if the statue might have been constituted by some different portion.) But if this were carried over to the action case, there would seem to be a possibly conflicting asymmetric dependence with the bodily movement's being the action's product. If so, we should have to say both that the action asymmetrically depends on the movement of the body and that the movement of the body asymmetrically depends on the action. ${ }^{19}$ Whether or not there is a genuine conflict here, however, turns on delicate issues surrounding the proper formulation of claims about metaphysical dependence. ${ }^{20}$ Still, it seems to me that working out the metaphysical relations between these various temporal entities is a daunting enough task on its own - so that we might wish to avoid making that task harder by insisting that constituent events also causally depend on the actions they constitute.

\footnotetext{
${ }^{18} \mathrm{~A}$ conversation with Olav Gjelsvik was instrumental in my coming to see the force of what follows.

${ }^{19}$ But perhaps the relevant analogy is with animate substances? And perhaps their dependence on their matter is different? Steward makes the comparison in 'Actions as Processes', 383. Also see Thompson, Life and Action, 112. I leave this possibility unexplored; the metaphysical waters seem especially deep here.

${ }^{20}$ For a helpful survey, see Correia, 'Metaphysical Dependence'.
} 
Of course it is open to Steward to maintain that bodily movements are what actions are causings of. But if there is anything to the foregoing worries, then there may be a difficulty in holding both that a bodily movement is the causal product of an action and that the two are related to one another as closely as a lump of bronze and the statue it constitutes. My suspicion is that we can maintain that bodily movements are what actions are the causings of only at the cost of introducing a degree of separation between the two which goes beyond that of constitution. (Recall Steward's claim that actions take place alongside the movements in which they result.) But then I think that we once again threaten the visibility of actions. ${ }^{21}$ For one wants to ask, albeit perhaps in a flat-footed and literal-minded manner, 'To which side is one to look in order to see the raising of the arm, as opposed to its rising?' We are now considering the action as a particular occurrence, but one that is separate from the only other obviously relevant visible occurrence. So, I suggest there is some tension in accepting that actions are visible while treating bodily movements as their causal results.

Let us recall premise (2) from Section II:

(2) If I am causing my arm to move, then there is an event of my arm's moving occurring.

Accepting the process/constituent-event distinction, we could endorse (2) and the ensuing denial of the Non-Identity Clause of the Separation Thesis and yet still deny the Causal Clause, that is (3). Consider, next, this alternative reading of (2):

(2') If I am causing my arm to move, then there is a process of my arm's moving occurring.

Here we have no reason in advance to think that the entailed process will not share all the properties of the action; there would then be no argument from Leibniz's Law in favour of our distinguishing the two. If the entailed process is 'what happens', then I should say that 'I do what happens'; and with bodily movements so conceived, both clauses of the Separation Thesis are false. Of course, armed with the process/constituent-event distinction we have no reason to choose between (2) and (2'): they are compatible.

V.

Here is Anscombe again:

[In] so far as one is observing, inferring etc. that [what one is doing] is actually taking place, one's knowledge is not the knowledge that a man

\footnotetext{
${ }^{21}$ I ignore the possibility of invoking part-whole relations, which Steward rejects. Steward, 'Do Actions Occur', 117.
} 
has of his intentional actions. By the knowledge a man has of his intentional actions I mean the knowledge that one denies having if when asked e.g. 'Why are you ringing that bell?' one replies 'Good heavens! I didn't know I was ringing it! 22

This can seem to be a plain truth: if someone is intentionally doing something, then ordinarily she herself knows what she is bringing about in acting, ${ }^{23}$ where what she is bringing about is being brought about intentionally. ${ }^{24}$ Moreover, this knowledge in intention is not grounded in observation or inference. But if in acting intentionally what one is doing is causing the distinct occurrence that the completion of the action requires - an arm's rising, say - then can one know without observation or inference what one is bringing about, for example that one's arm is rising? Once again, I suggest that one cannot.

Now, let us ignore the idea of movements as action-constituting events and think of them as separate from actions. And let us grant that we know what we are doing intentionally without observation or inference. The Separation Thesis states that an intentional action is the causing of an occurrence, which causing is distinct from the occurrence caused. This suggests that, whilst one may have non-inferential and non-observational knowledge that one is exercising one's power to raise an arm, say, that there is a successful consummation of such an exercise in an unfolding occurrence is not something one has been put in a position to know in like manner. For the intended movements that one's limbs make, when one acts, are not themselves intentional actions on this view. Whatever the logical relations between them, we seem to confront two distinct facts: that one is raising one's arm and that it is going up. And so, given one's raising of one's arm is not as such its rising, it is hard to see why one's non-observational and noninferential knowledge that one is acting should reach all the way to one's knowing that the non-identical resultant events are occurring. It then seems

\footnotetext{
${ }^{22}$ Anscombe, Intention, $50-1$.

${ }^{23}$ Why 'ordinarily'? Perhaps there are (bad) cases where one does not know that the intended results of one's action are occurring, or (differently) knows this only through observation or inference. (On the latter, see note 35.) But, if I am right, then the Separation Thesis conflicts with the possibility of (as I see it) standard cases.

${ }^{24} \mathrm{By}$ 'what one is bringing about' I mean the descriptions under which one's action falls, for example whether one's egg-breaking is also an omelette-making. One might causally produce, and so bring about, some distal event which then allows one relevantly to re-describe one's action; this is how the Separation Thesis encourages one to think quite generally, but it clearly is not how to think about all cases, for example the egg-breaking/omelette-making. Furthermore, if one is bringing something about, there is the suggestion that one is employing some means to do so. But it seems odd to say that in the basic case I bring about my arm's rising by means of raising it. See Baier, 'Act and Intent'. But given the Separation Thesis's distinction between actions and their results, I am unsure how else to phrase the conditional concerning knowledge in intention, in order to bring it into contact with the view.
} 
as if one's knowledge that one is raising one's arm will need supplementing in order that one should know that one's arm is rising: one would have to rely on observation or inference to come to know about the occurrences in which one's actions result - to know whether one's arm is rising when one is raising it.

The point is perhaps easier to see if we emphasize the continuous nature of (most) bodily action. ${ }^{25}$ Let us return to Rachael, who is intentionally raising her arm. If she is to have raised it, then there must be an event of its so rising which is articulable into a set of phases, progress through which to completion satisfies her having raised her arm that far. Given the Separation Thesis, however, her action itself is restricted to her initiating and then maintaining the movement that her arm makes; she must guide and sustain the progress of that distinct event through to completion. The problem then is that her knowledge that she is raising her arm, on such a view, does not itself seem to provide for her needed knowledge to the effect that her arm is progressing towards being higher. Rather, Rachael will have to monitor that distinct result in which the intended efficacy of her action consists. Here it is worth quoting a passage that follows Steward's claim that actions occur alongside, and at the same time as, bodily movements: 'I settle things not only by initiating motor activity but also by continuing it; by refraining, for example, from vetoing the original instruction or from altering it. ${ }^{, 26}$ Here one's actions have been disconcertingly distanced from the movements of one's body, where one's continued role amounts to an ability to intervene in an event whose progress one has set in motion. The actual efficacy of Rachael's action of raising her arm then appears as something to which she is blind, unless it is supplemented by some other epistemic resources. In Anscombe's words, when it comes to the movements of one's body on this view 'the facts, reality, are prior and dictate what is to be said, if it knowledge'. ${ }^{27}$

Another way of putting this point is to say that, given the Separation Thesis, it is hard to see how the agent could know without observation or inference that her raising of her arm falls under the description 'an arm's rising'- though given the Thesis it seems that she might know, for all that, that she is raising her arm. But it might be doubted whether an agent could know that she is raising her arm without knowing that it is rising. It is surely plausible that an agent's conceptual mastery of the act-type raising depends upon her grasp of the fact that there is a causing properly so described only where there is the relevant rising. However, securing this necessity at the level of descriptions only moves the issue upstream: the agent will need to know about the results of her causing, presumably through observation or

\footnotetext{
${ }^{25} \mathrm{My}$ argument here is especially indebted to Lavin, 'Must There Be Basic Action?'.

${ }^{26}$ Steward, A Metaphysics for Freedom, 46.

${ }^{27}$ Anscombe, Intention, 57.
} 
inference, in order to be in a position to know whether she is raising her $\operatorname{arm}^{28}$

VI.

I think that we still face an important question: Is the conditional concerning knowledge in intention, which I took as a premise, too strong? It is worth recalling that in the third-person case I was able to make the ad hominem point that Steward herself insists on our capacity to perceive the actions of others. Here the situation is different: perhaps Steward would either deny that there is a 'cognition condition' on intentional action tout court, ${ }^{29}$ or try to weaken my formulation of it.

Perhaps an agent does (only) know about the intended results of her actions through observation or inference. After all, if one could know that one is raising one's arm without yet knowing that it is rising, then would not the relevant instance of the verb schema (S) license one to form the belief that it is rising? On the other hand, perhaps acting intentionally requires some proprioceptive awareness of one's body and perceptual awareness of the surroundings with which one interacts. Would it then be implausible to think that one also (only) knows that one's arm is rising through proprioception or perception? ${ }^{30}$

I cannot here explore the questions whether, to what extent and why intentional action meets a cognition condition. But it seems to me extremely odd to think that one might know that one is raising one's arm without knowing that it is rising; or that we might avoid this by requiring that an agent's knowledge that she is raising her arm depend on the deliverances of her senses. And, more generally, one's capacity to act intentionally may depend in some way on the operation of one's senses without one's sensory knowledge serving as a ground of one's knowledge that one's arm is rising.

If I am right, the Separation Thesis sits uneasily with a particularly strong formulation of a cognition condition on intentional action. And I think this is enough to put the Thesis in question.

\section{VII.}

Let me return to the reductio argument of Section II, which reached the absurd conclusion (5).

\footnotetext{
${ }^{28}$ Given this, clearly it could not be the raising from which one infers the rising.

${ }^{29}$ As Small so names it. Small, 'Practical Knowledge'.

${ }^{30}$ Of course the literature abounds with alleged counter-examples to the claim that intentional action entails knowledge. For helpful discussion, see Gibbons, 'Seeing What You're Doing'; Small, 'Practical Knowledge'.
} 
(5) My moving my arm is an event which is causing itself.

My suggestion is that we reject premise (3).

(3) My moving my arm is identical with my causing of an event of my arm's moving.

But what might be said in (3)'s favour? Well, it seems that a perfectly natural way of putting the first premise would be this:

(1') If I am moving my arm, then I am causing its moving.

But then, given premise (2) it will be natural to hear this as saying:

$\left(1^{\prime \prime}\right)$ If I am moving arm, then I am causing an event of its moving.

It now becomes easier to think of my causing (my doing causing, as it were) as a distinct item with which my moving of something is to be identified.

We need not accept the move from (1) to (1"), however. The phrase '...my arm to move' in premise (1) is not obviously transformable into '... an event of its moving. ${ }^{31}$ On the face of it the 'relata' introduced by the causal schema for the relevant class of verbs seem to be two continuants, related by parthood in the case on which we have been focusing - namely, an agent and her arm. But then abandoning (3) and the idea that actions causally join one to an occurrence, what are we to make of (4)? Well, depending on whether we read (2) as introducing processes or events, as per Section IV, we should have either:

(4') My moving my arm is (a process which is) constituted by an event of my arm's moving.

or:

(4') My moving my arm is (a process which is) identical with a process of my arm's moving.

Again, we need not choose between these-but I shall pursue (4"). If we accept (4'), we shall think of my moving my arm and its moving as identical, and describable again as my causing something to change. That is, my moving my arm and its moving would form, irreducibly, two aspects of a single causal process, at the two poles of which would stand me, the agent, and my arm, the patient. ${ }^{32}$

\footnotetext{
${ }^{31}$ See Stout, 'What Are You Causing in Acting?', 104.

${ }^{32}$ Anton Ford develops this way of thinking about actions as transactions. He, however, is suspicious of the idea that basic actions like arm-raisings are transactional. Here I cleave to the
} 
The view we reach now has an Aristotelian flavour, and it is an interesting question whether it is ultimately defensible. ${ }^{33}$ I cannot settle that question here, but I suggest that we have good reasons stemming from the epistemology of action to pursue it.

Taking a view such as this, one has to insist, as others have, that there is a distinction in kind between those bodily movements that are actions and those that are not-reflex movements and the like. For we can now no longer help ourselves to the idea that there being a bodily movement is a condition that belongs in a conjunctive definition of what an action is. We must say instead that there are two determinations of the determinable 'bodily movement', one of which is of necessity an action. ${ }^{34}$ With this in mind, it should become clear that there is no longer any general problem of perceiving actions: even if we err in particular cases, often enough the very movements we witness will be actions. Moreover, in principle there need be no difficulties surrounding the idea of our causing such things as a table to move, a window to open or a house to be built; our causal powers extend beyond our skin. Indeed, a vast number of verbs for ascribing actions pick out actions of just this kind. But because the unfolding material occurrence in such cases is not distinct from the intentional exercise of our causal power, there is no problem concerning our having to observe or infer that events that are independent of our actions are occurring. ${ }^{35}$ If we know what we are intentionally doing, then we know what change we are thereby effecting.

\section{Acknowledgements}

Many people helped in the writing of this paper. For comments on earlier drafts, my thanks to Luke Brunning, Yair Levy, Lea Salje, Rory Madden, Jennifer Hornsby and Lucy O'Brien. I also benefitted from participants' comments at the UCL PhD Work-in-Progress Group and the CSMN Oslo workshop on A Metaphysics for Freedom, 5-6 April 2013. Finally, thanks to Olav Gjelsvik for a crucial conversation at the latter occasion as well as to Helen Steward for providing such a helpful response.

\footnotetext{
apparently transitive nature of raising, as suggested by the linguistic surface. Ford, 'Action and Passion'.

${ }^{33}$ See Lear, Aristotle, 30-2.

${ }^{34}$ See, for example, Haddock, 'At One with Our Bodies'.

${ }^{35}$ Further to note 23: perhaps there are occurrences that can be considered intentional actions of ours which are not themselves exercises of our powers, but are so considered by dint of their having been brought about (a) by an occurrence that is an exercise of our causal power and (b) in line with a belief on the agent's part as to the likelihood of her action's creating the relevant occurrence. Perhaps some projectile cases are like this. Plausibly here perception will be necessary in order to know what one is bringing about, for example whether one's pressing the button is properly described as a sinking of the battleship. But it is far from obvious that most actions are of this kind. Compare: building a house, walking to school, eating a cake.
} 


\section{References}

Alvarez, Maria, and John Hyman. 'Agents and Their Actions'. Philosophy 73, no. 2 (1998): 219-45.

Anscombe, G.E.M. Collected Philosophical Papers Volume 2: Metaphysics and the Philosophy of Mind. Oxford: Blackwell, 1981.

Anscombe, G.E.M. Intention, 2nd ed. London: Harvard University Press, 2000.

Baier, Anette. 'Act and Intent'. Journal of Philosophy 67, no. 19 (1970): 648-58.

Correia, Fabrice. 'Metaphysical Dependence'. Philosophical Compass 3, no. 5 (2008): 1013-32.

Crowther, Thomas. 'The Matter of Events'. Review of Metaphysics 65, no. 1 (2011): 3-39.

Dretske, Fred. 'Perception and Other Minds'. Nov́s 7, no. 1 (1973): 34-44.

Ford, Anton. 'Action and Passion'. Unpublished manuscript.

Gibbons, John. 'Seeing What You're Doing'. In Oxford Studies in Epistemology, vol. 3, ed. Tamar Szabo Gendler and John Hawthorne, 63-85. Oxford: Oxford University Press, 2010.

Haddock, Adrian. 'At One with Our Bodies, But at Two with Our Actions'. Philosophical Explorations 8, no. 2 (2005): 157-72.

Hornsby, Jennifer. Actions. London: Routledge, 1980.

Hornsby, Jennifer. 'Actions and Activity'. Philosophical Issues 22, no. 1 (2012): 233-45.

Lavin, Douglas. 'Must There Be Basic Action?'. Nov́s 47, no. 2 (2013): 273-301.

Lear, Jonathan. Aristotle: The Desire to Understand. Cambridge: Cambridge University Press, 1988.

Small, Will. 'Practical Knowledge and the Structure of Action'. In Rethinking Epistemology, vol. 2, ed. Gunter Abel and James Conant, 133-228. Berlin: de Gruyter, 2012.

Steward, Helen. 'Do Actions Occur Inside the Body?'. Mind and Society 1, no. 2 (2000): 107-25.

Steward, Helen. A Metaphysics for Freedom. Oxford: Oxford University Press, 2012.

Steward, Helen. 'Actions as Processes'. Philosophical Perspectives 26, no. 1 (2012): 373-88.

Stout, Rowland. 'What Are You Causing in Acting?'. In Causing Human Actions: New Perspectives on the Causal Theory of Action, ed. Jesus Aguilar and Andrei Buckareff, 101-114. London: MIT Press, 2010.

Thompson, Michael. Life and Action. London: Harvard University Press, 2008. 